العدد الحادي والعشرون يناير · · r ج ج

\title{
أثر التفاعل بين نهط المساعدة (المعلم) وأسلوب التعلم (المعتمد/ المستقل) في الرهلات المعرفية عبر الويب على تنمية التصصل المعرفي لدى تلاميذ المرحلة الإعدادية
}

\author{
أ.م.د/ مصطقى سلامة عبد الباسط \\ أستاذ مساعد بقسم تكنولوجيا التعليم والحاسب الآلي التي \\ كلية التربية النوعية- جامعة المنوفية
}

أ. أد/ أحمد مصطفي كامل عصر أستاذ ورئيس قسم تكنولوجيا التعليم كلية التربية النوعية- جامعة المنوفية

\author{
رحاب شعبان مشحوت غراب \\ معلم حاسب آلي - إدارة منوف التعليمية فئواب
}

ملخص البحث: - 20 - 20

هدف البحث إلى الكثف عن أثر التفاعل بين نمط المساعدة (المعلم) وأسلوب التعلم (المتتمد/ المستقل) في الرحلات المعرفية عبر الويب على تتمية التحصيل المعرفي لدى تلاميذ

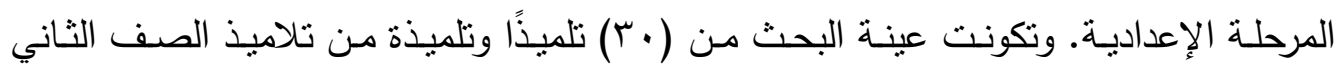
الإعدادي بمدرسة سدود الإعدادية المشتركة، وتم تقسيمهم إلى مجموعتين تجريبيتين وهم معتمد الإعن يستخدم الرحلة المعرفية التي تحتوي على نمط مساعدة المعلم، والثانية مستقل يستخدم الرحلة المعرفية التي تحتوي على نمط مساعدة المعلم، وقد تمنلت أدوات البحث في اختبار تحصيلي لمطي لقياس الجانب المعرفي لدى التلاميذ. وقـد قامـت الباحثـة بتطبيـق أسـاليب المعالجـة الإحصـائية المناسـبة باسـتخدام البـرامج

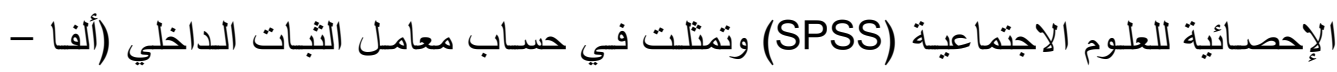

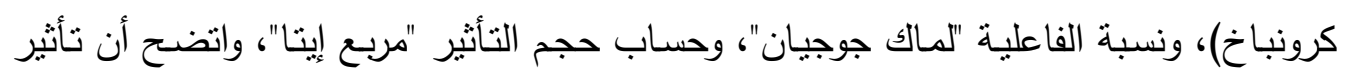

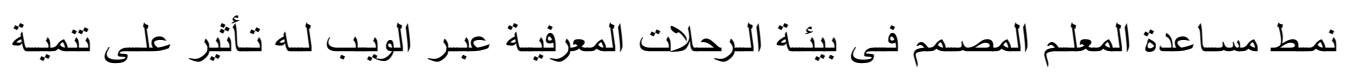
التحصيل المعرفي لدى تلاميذ المرحلة الإعدادية.

الكلمات الرئيسة Keywords:

نمط المساعدة، مساعدة المعلم، أسلوب التعلم، الرحلات المعرفية عبر الويب. 


\section{Research summary:}

This research aims to discover the effect of the interaction between the assistance style (teacher) and the learning style (dependent / independent) in web quests on the internet on the development of cognitive achievement of students in the preparatory school. The sample of the research consisted of (30) male and female students from the second year of middle school at the Sodoud Preparatory School. They were divided into two experimental groups, and they are certified using the web quest that contains the teacher's help pattern, and the second is independent that uses the web quest that contains the teacher's help pattern. The research tools are an achievement test to measure the cognitive side of the students.

The researcher applied the appropriate statistical processing techniques using SPSS. The calculation of the coefficient of internal stability (alphacronbach), the efficiency ratio of "MacGujian" and the calculation of the effect size of the "ETA box",

And it became clear that the effect of the designed teacher assistance style in the environment of web quests on the internet has an impact on the development of cognitive achievement of students in the preparatory school.

Keywords: Help style, teacher assistance, learning style, web quests. 
تشهد نظم التعليم في الوقت الحالي تطورات سريعة متعاقبة نتيجة الثورة الهائلة في مجال

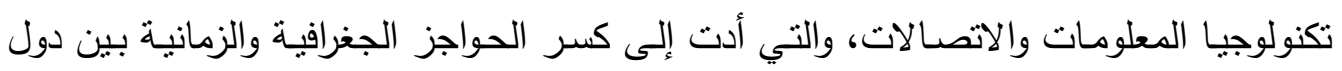

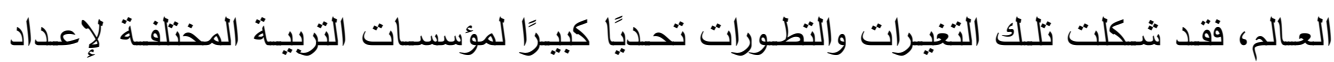

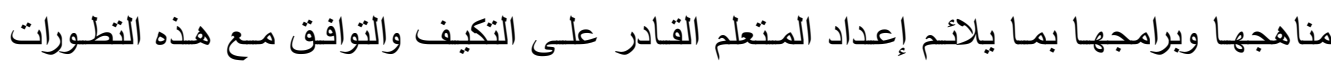

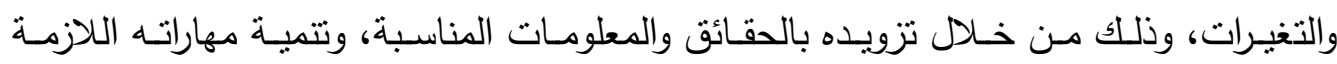

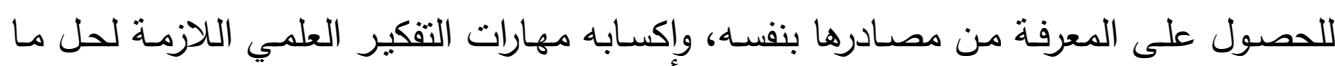

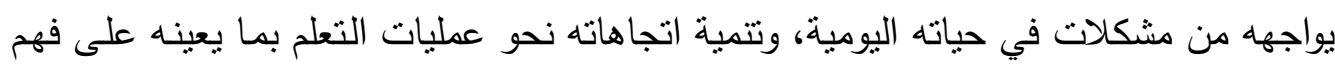

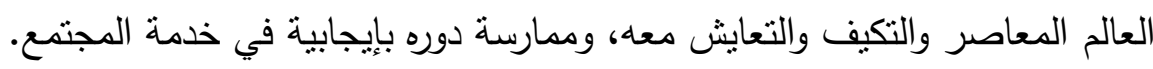
ومن بين أهم النشاطات التي تتعلق بشبكة الانترنت وتهم مستخدمي الثبكة هي عملية البحث عن المعلومات، وللقيام بهذه المهمة توافرت على شبكة الانترنت محركات بحث بثت عملاقة

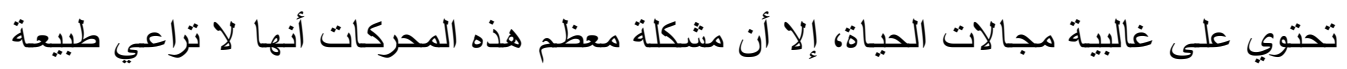

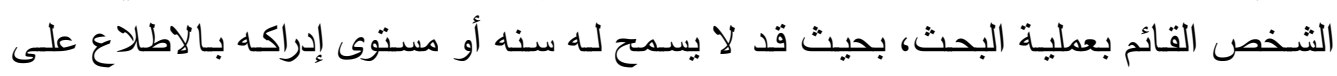

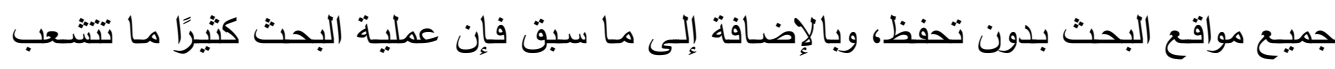

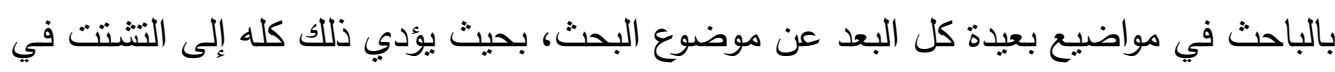

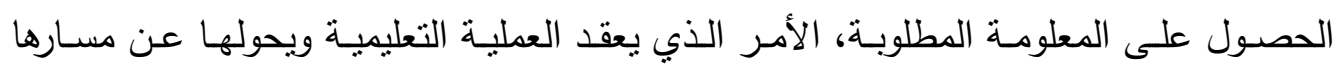

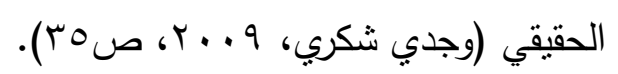

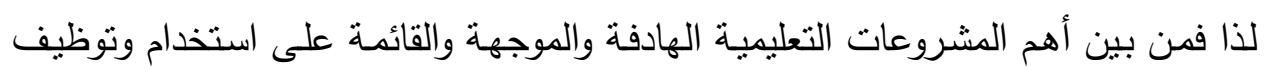

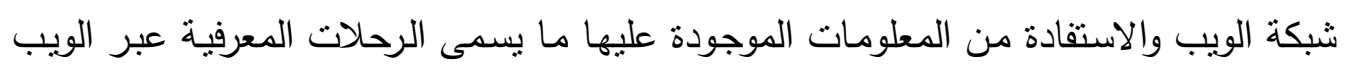

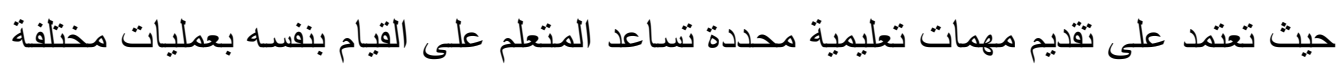
من البحث والاستكثاف للمعلومات عبر الويب، واستخدام وتوظيف هذه المعلومات وليس مجرد الحصول عليها.

الرحلات المعرفية تعكس فكرة التدريس المعاصر الذي يعتمد على دمج التكنولوجيا في

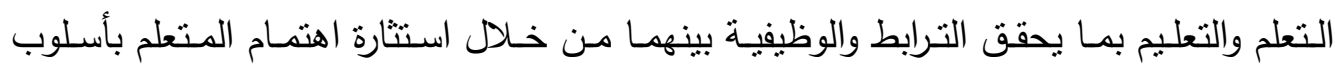

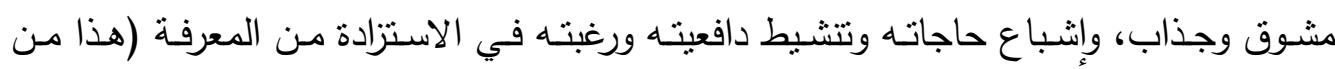

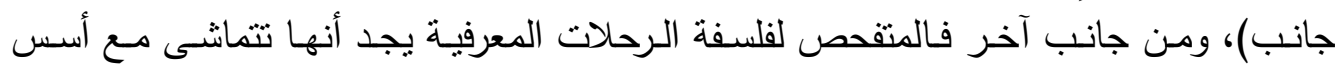

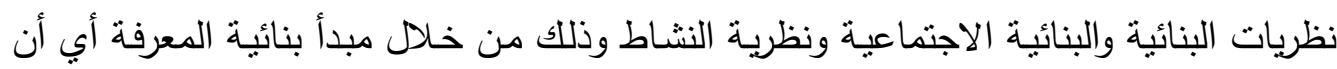

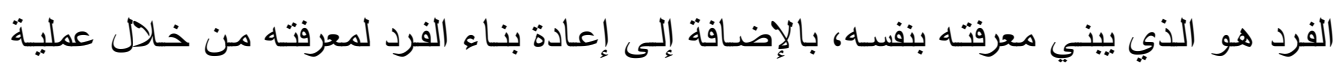

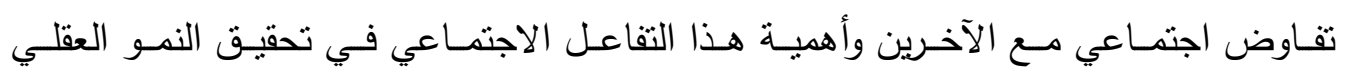


(والتخلص من التمركز حول الذات) وبناء الخبرة القائمة على النشاط (وداد عبد السميع، ياسر

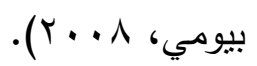

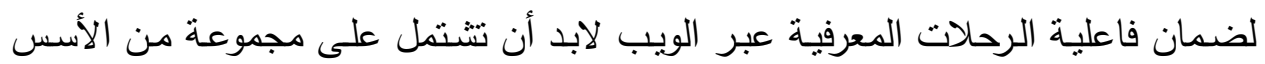

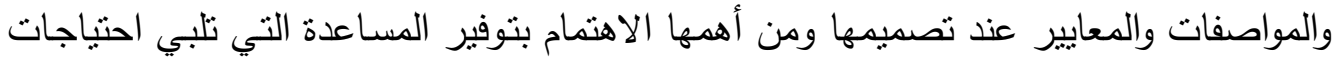

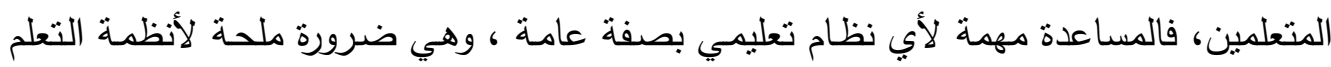

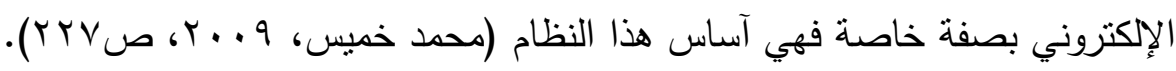
يعد ثقديم المساعدة من أهم المعالم والركائز الأساسية في بيئة التعلم القائم على الويب؛

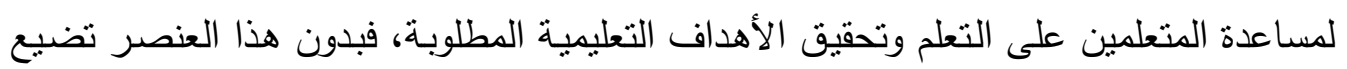
بعض معالم البيئة التي تتسم بالمرونة وتعلم المتعلم ودوره كمنتج لمعرفته، ويضيع دور المدئ المعلم

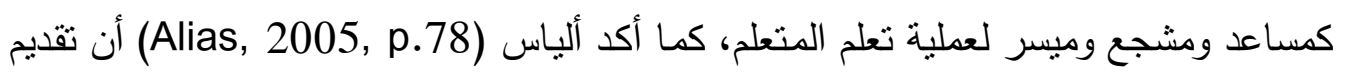

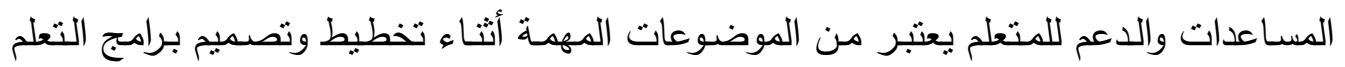

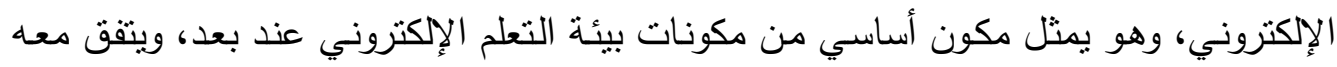

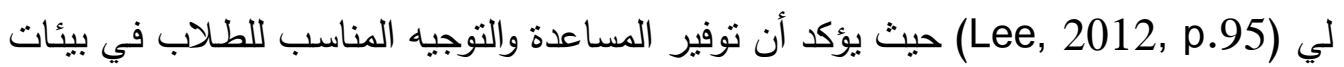

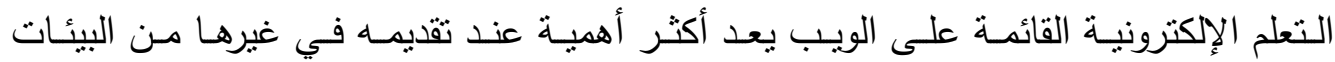

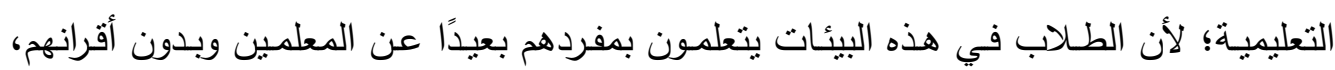
ويجب توفير الدعم والمساعدة اللازمة لهم عندما يحتاجون إليها. تعددت مصادر تقديم المساعدات التعليمية في بيئة التعلم القائم على الويب، حيث أكد كل من بانتامبكار وهوبسيكر (Puntambekar and Hubscher,2005,p.36) أن تقديم المساعدات التعليمية لم يعد يقتصر على التفاعلات التي تتم بين المعلم والمتعلمين فقط، ولكن

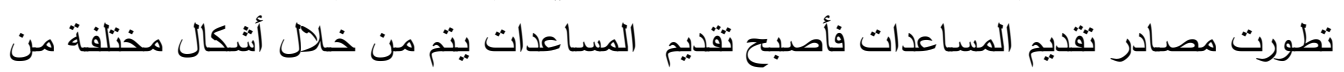
أدوات وبرامج الدعم الكمبيوترية ومصـادر تعليمية أخرى لمسـاعدة المتعلم على التعلم بفعالية.

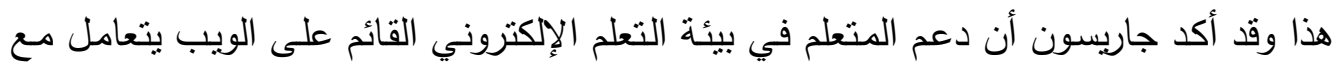

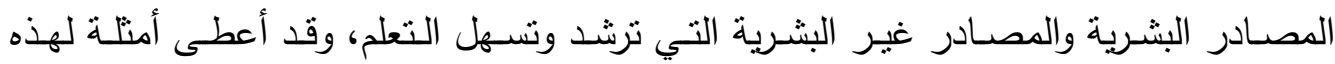

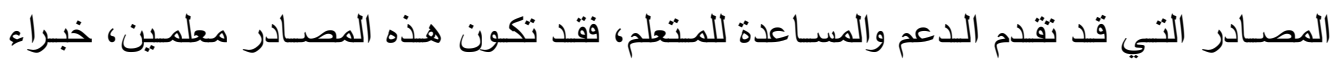

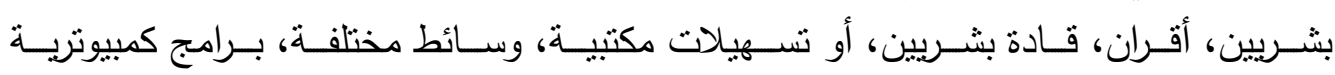

.(Farajollahi\& Moenikia as cited at, 2010, p.148)

تختلف أنماط المساعدة الإلكترونية في بيئة التعلم القائم على الويب ومنها مساعدة بشرية

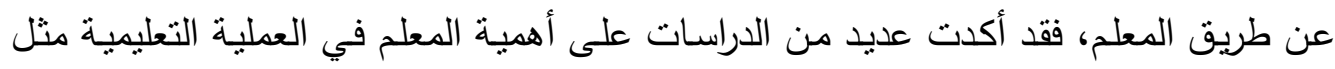

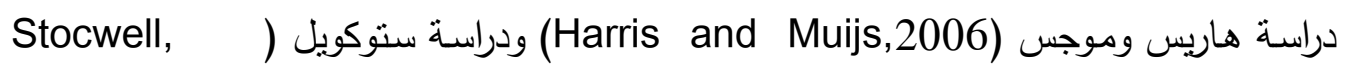




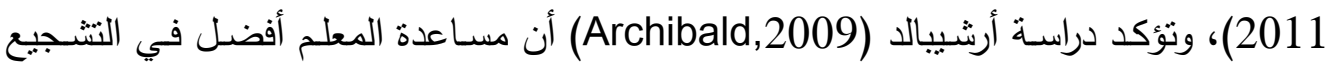
على الإنجاز والحث على المشاركة وتوجيه الطلاب نحو تحقيق نواتج التعلم والأهداف التعليمية المنشودة بشكل فعال.

ويعد أسلوب التعلم أحد المتغيرات التي بظهر فروفًا فردية بين الأفراد ويرتبط بمتغيرات

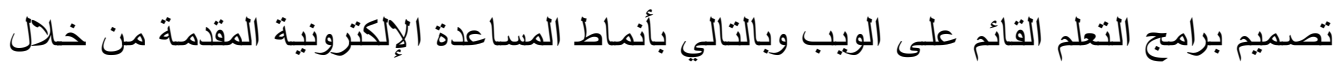

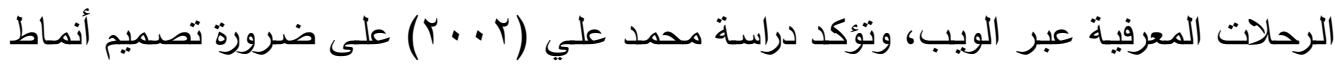

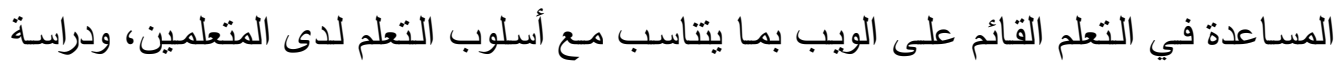

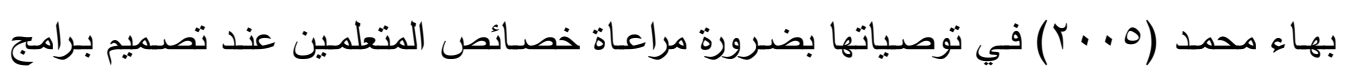

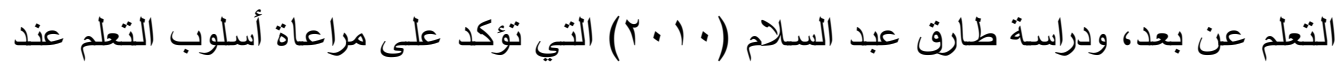
توظيف أنماط المساعدة في برمجيات الوسائط المتعددة.

\section{بالنظر ومراجعه ما تناولته البحوث والدراسات السابقة يتضح ما يلي:}

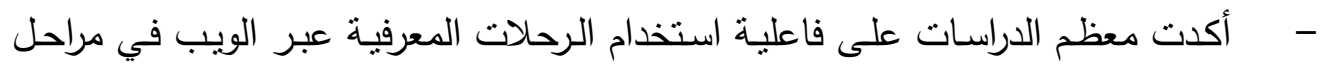

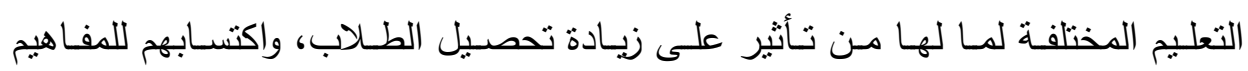
العلمية.

- - أكدت معظم الدراسـات على أهمية توافر المساعدة المطلوبـة للمتعلمين في برامج التعلم القائم على الويب لتلبي احتياجات المتعلمين.

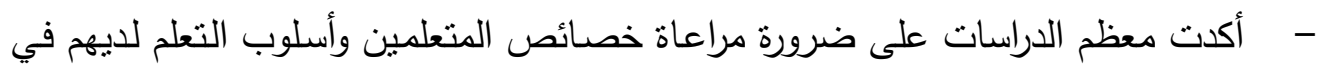

$$
\text { التعلم القائم على الويب. }
$$

- لم تنتاول أي دراسة تأثثر التفاعل بين نمط المساعدة (المعلم) وأسلوب التعلم (المعتمد/ المستقل) في الرحلات المعرفية عبر الويب على تنمية التحصيل المعرفي في حدود علم الباحثة.

من كل ما سبق اهتمت الباحثة بضرورة دراسـة تأثير التقاعل بين نمط المساعدة (المعلم) وأسلوب التعلم (المعتمد/ المستقل) في الرحلات المعرفية عبر الويب بما يسمح للتلاميذ نتمية التحصيل المعرفي لديهم.

\section{الإحساس بمشكلة البحث:}

نبع الإحساس بمشكلة البحث من عدة مصادر يمكن توضيحها فيما يلي:

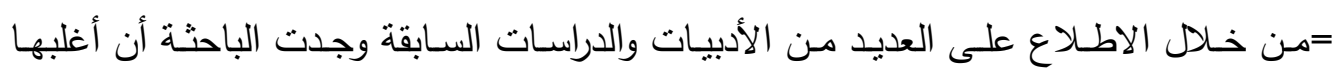

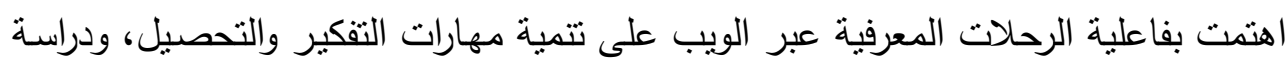

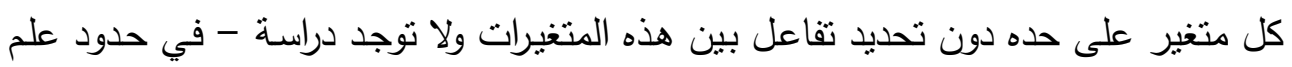


الباحثة- قامت بدراسة تأثثر التفاعل بين نمط المساعدة (المعلم) وأسلوب التعلم (المعتمد/

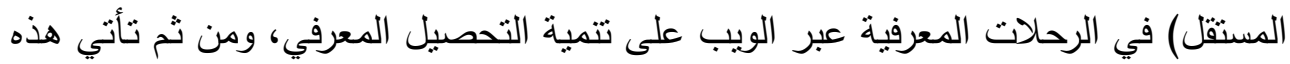

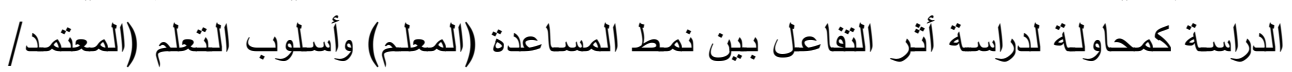

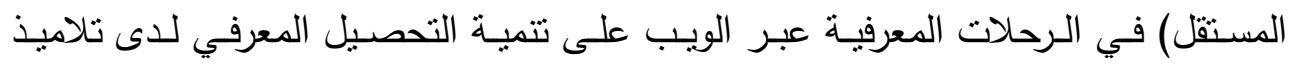
المرحلة الإعدادية.

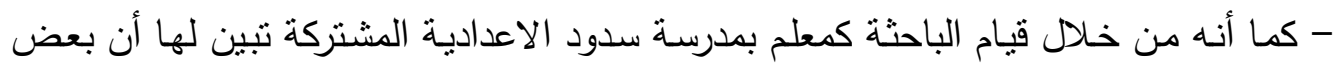

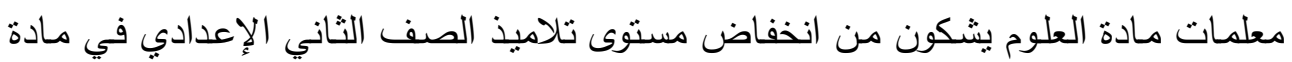

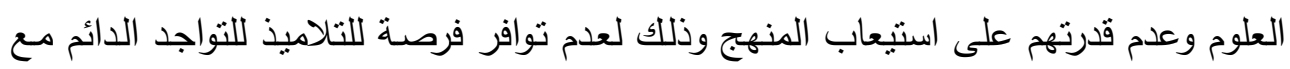
المعلمة لتقديم المساعدة اللازمة لهم وهذا لاحظته الباحثة من خلال سجل درجات التلاميذ.

\section{مشكلة البحث:}

على ضوء ما سبق يمكن تحديد مشكلة البحث في العبارة التقريرية التالية: "وجود حاجة

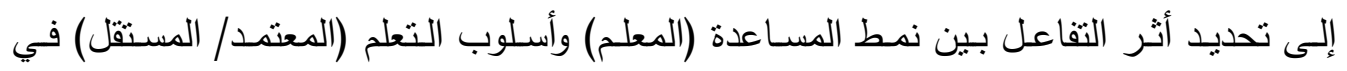
الرحلات المعرفية عبر الويب على تتمية التحصيل المعرفي لدى تلاميذ المرحلة الإعدادية". أسئلة البحث:

يتطلب البحث الحالي الإجابة عن السؤال الرئيس التالي:

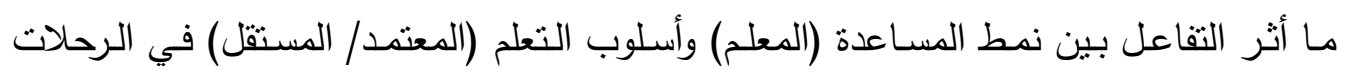

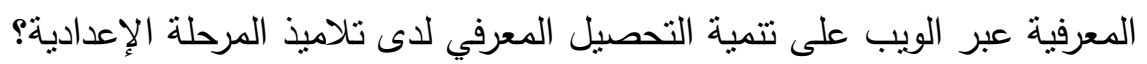
ويتفرع منه الأسئلة الفرعية التالية: ا. ـ ما المعايير الواجب توافرها عند تصميم الموقع التعليميى القائم على الرحلات المعرفية

$$
\text { عبر الويب؟ }
$$

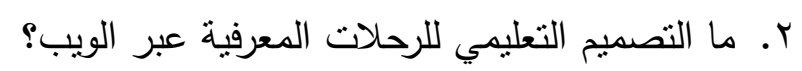

r. ما أثز نمط المساعدة (المعلم) في الرحلات المعرفية عبر الويب على لتمدية المعية التحصيل

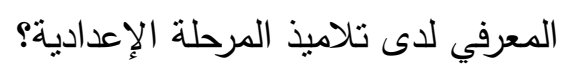

ع. ما أثر أسلوب التعلم (المعتمد/ المستقل) في الرحلات المعرفية عبر الويب على تتمية

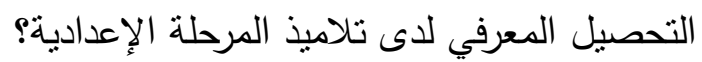

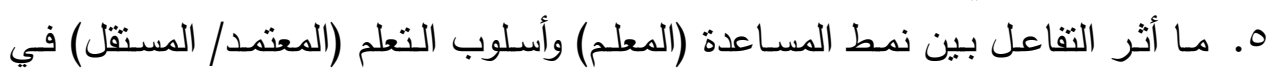

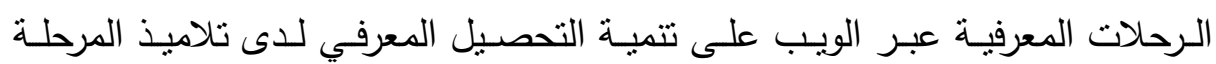




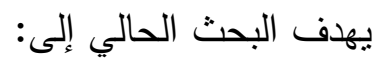

ا. التعرف على أثر نمط المساعدة (المعلم) في الرحلات المعرفية عبر الويب على تتمية التحصيل المعرفي لدى تلاميذ المرحلة الإعدادية.

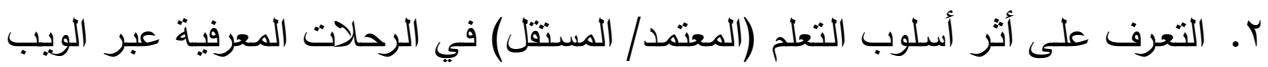
على تتمية التحصيل المعرفي لاى تلاميذ المرحلة الإعدادية.

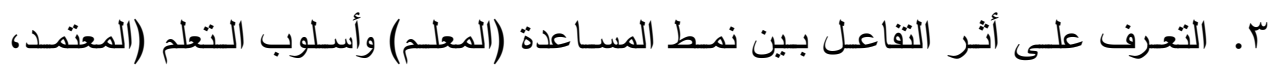
المستقل) في الرحلات المعرفية عبر الويب على تتمية التحصيل المعرفي لدى تلاميذ المرحلة الإعدادية. أهمية البحث: - 20 تمثلت أهمية البحث الحالى فى إمكانية إسهام نتائجه فيما يلي: ا. تشجيع التلاميذ على بناء المعارف بأنفسهم مما يؤكد على دورهم الأساسي في في العيدة العملية التعليمية. r. تتمية مهارات التلاميذ لاستخدام شبكة الانترنت والتعامل معها في البحث والتقصي

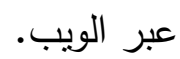
r. توجيه التلاميذ نحو نمط المساعدة الذي يتتاسب مع أسلوب تعلمهم بما يساعدهم في تتمية التحصيل المعرفي لديهم. توحئ. ـ. توجيه أنظار المعلمين على استخدام الرحلات المعرفية عبر الويب في جميع المراحل التعليمية. ه. تقديم نتائج تساعد القائمين على تصميم الرحلات المعرفيـة عبر الويب اختيار نمط المساعدة الذي يتتاسب مع أسلوب تعلم التلميذ لتحقيق التعلم الفعال.

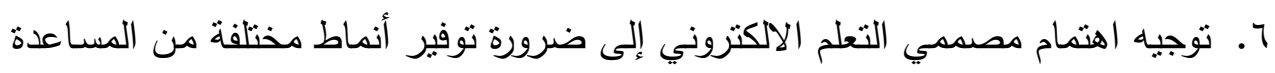
في بيئة التعلم الالكتروني لمواجهة الفروق الفردية.

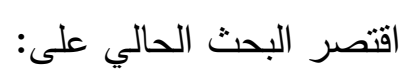

ا. تلاميذ الصف الثاني الإعدادي بمدرسة سدود الإعدادية المشتركة إدارة منوف التعليمية

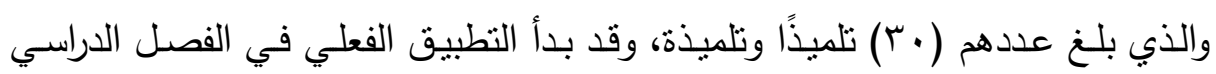

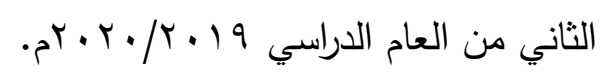




$$
\text { r. r. نمط المساعدة (المعلم). }
$$

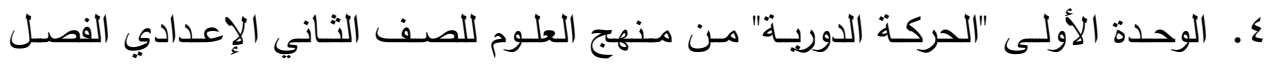
الدراسي الثاني وذللك لاحتوائه على الجوانب المعرفية.

فروض البحث:

يسعى البحث للتحقق من صحة الفروض التالية:

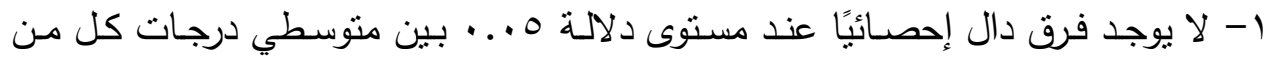

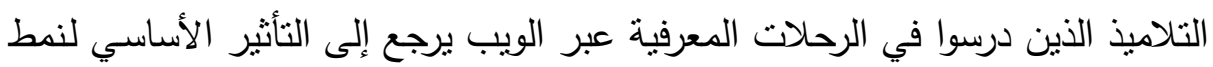

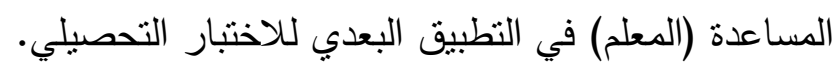

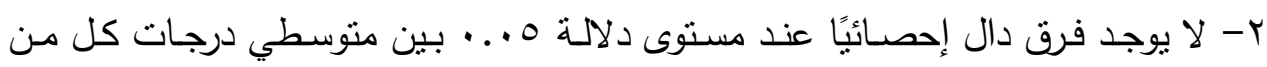

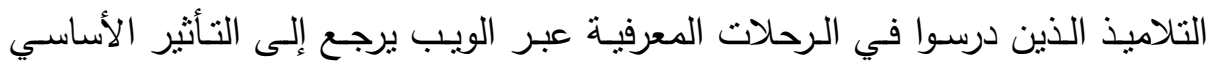

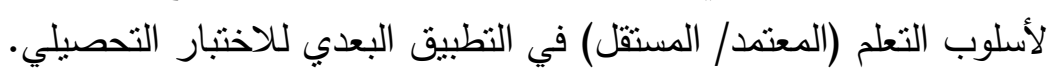

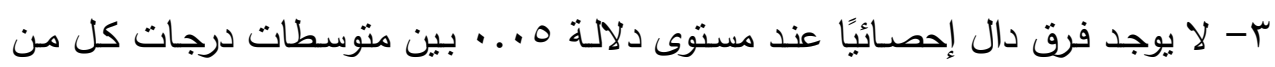

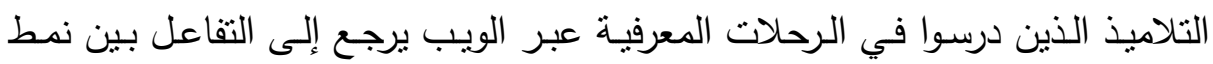

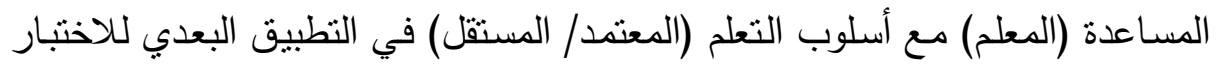

$$
\text { مصطلحات البحث: التصيلي. }
$$

تعرفها الباحثة إجرائيًا بأنها مجموعـة المسـاعدات والتوجيهات التي تقدم للتناميذ خـلال الرحلـة المعرفيـة عبـر الويـب مـن خـلال الأدوات المختلفــة المتـوافرة فـي بيئـة الـتعلم القـائم

$$
\text { على الويب. }
$$

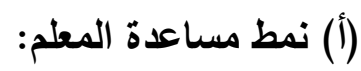

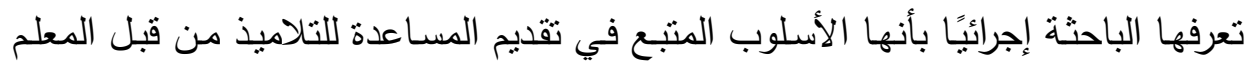

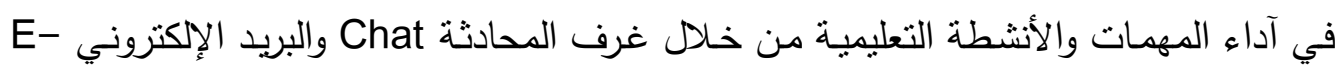
التي توفرهـا الرحلة المعرفية عبر الويب وذلك لتنفيذ المهوات التعليميـة المطلوبـة منهم وصولًا لتحقيق الأهداف التعليمية المحددة.

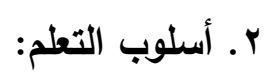

هو الاسلوب الذي يستخدمه الفرد في تصنيف إدراكاته للبيئة وتتظيمها، أو الطريق التي يستجيب به للمثيرات، والنهج الذي يسلكه في السبطرة عليها ونوجيهها. 
r. الرحلات المعرفية عبر الويب:

يمكن تعريفها إجرائيًا بأنها مجموعة من الأنشطة التعليمية الاستكثافية نم إعدادها لتحقيق

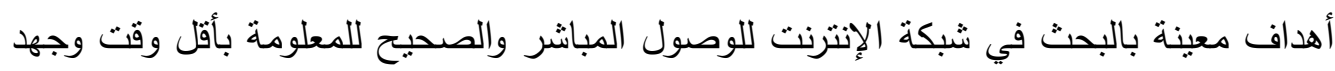
مدكنين وتتمية المهارات لدى التلاميذ. ع. التحصيل: يمكن تعريفه إجرائيًا بأنه قياس قدرة الطالب على استيعاب المواد الدراسية المقررة ومدى قدرته على تطبيقها من خلال وسائل وأدوات قياس، أو هي الدرجة التي يحصل علئل عليها التلميذ في الاختبار البعدي.

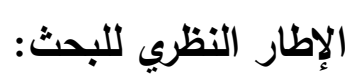
تضمن الإطار النظري ثلاث محاور رئيسة وهي بيئة الرحلات المعرفية عبر الويب، نمط

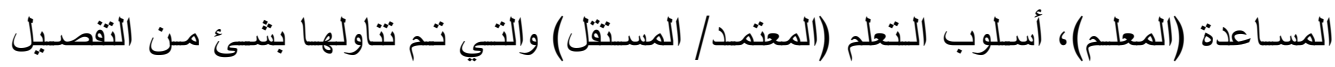
كما يلي: المحور الأول: الرحلاث المعرفية عبر الويب: مفهوم الرحلات المعرفية عبر الويب (Web Quest):

يعرفها كل من دجرو وسيكر (Dogru\&Seker,2012,p.96)؛ واكبز وبويد ( Ikpeze)

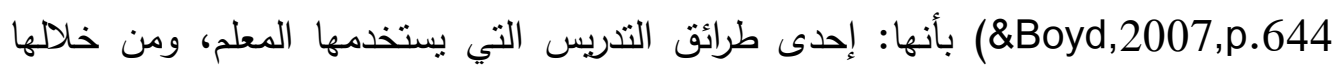

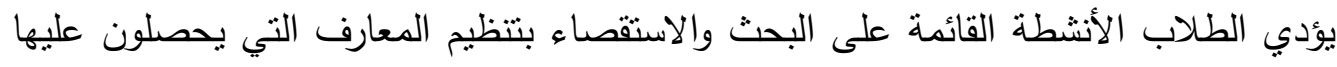

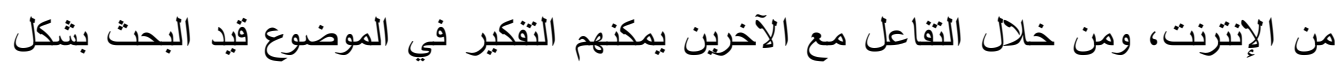
ناقد؛ مما يؤدي على نمو المهارات الذهنية لديهم.

ويمكن تعريفها إجرائيًا بأنها مجموعة من الأنشطة التعليمية الاستكثافية تم إعدادها

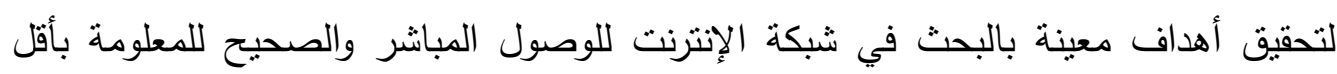
وقت وجه ممكنين وتتمية المهارات لدى التلاميذ.

عناصر ومكونات الرحلات المعرفية عبر الويب:

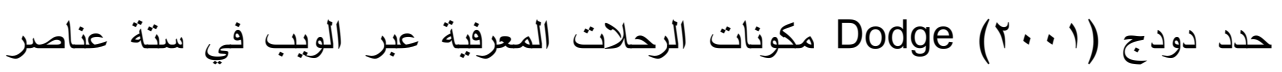

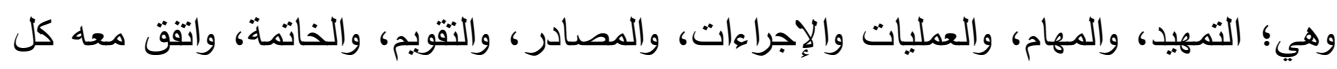

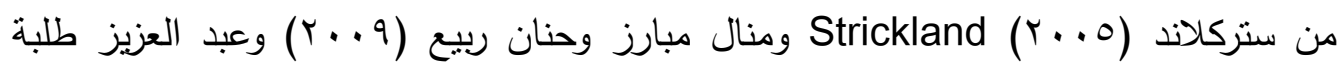

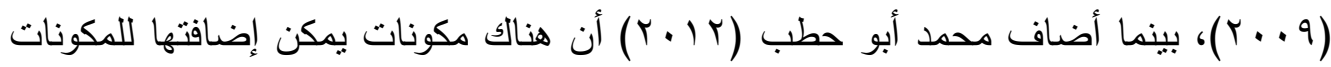

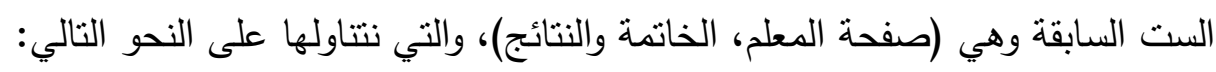


إ - التمهيد (المقدمة) Introduction

الهذف منه هو توضيح الفكرة العامة للرحلة المعرفية، وما هو مطلوب من كل متعلم أنثاء الرحلة، ويتم ذلك في صورة قصة مشوقة ومثيرة بالنسبة للمتعلم، وذلك بهدف إثارة دافعية

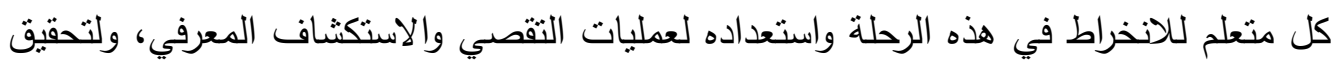
ذللك يجب أن تكون المقدمة: - تحمل صياغة مشوقة للمتعلم لتتفيذ الرحلة المعرفية.

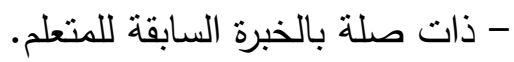
- ذات صلة بالأهداف المستقبلية للمتعلم.

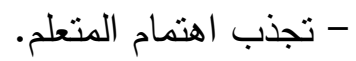

:Tasks المهام

المهمة هي نشاط قابل للتتفيذ يحظى باهتمام المتعلم، هذه الأنشطة من نوعية "اقرأ

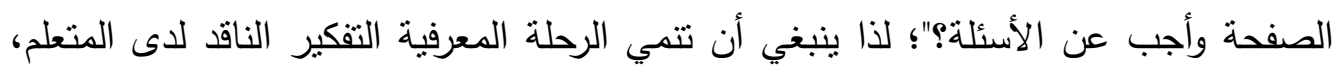

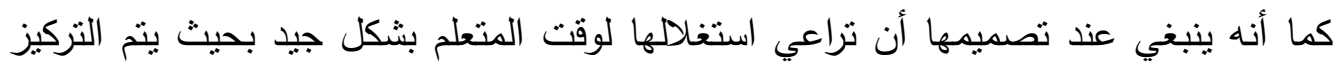

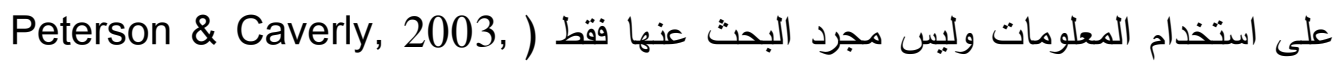
.(p.134

ب- العمليات والإجراءات Procedures:

تتمثل في المراحل التي يمر بها المتعلم أثناء القيام بالمهمة المطلوبة منه، لذا يقدم دليل إرشادي للمتعلم لاستكمال تلك المهام، ويتم وصف خطوات العمل داخل الرحلة المعرفية وصفًا واضحًا يشمل قواعد العمل والاستراتيجيات المتبعة بها (Ayfer \& Steeve, 2006, p.76). צ - المصادر Resources:

يتم تقديم قائمة بالمصادر التي تساعد المتعلم في إنجاز المهام المطلوبة منه، ويراعى أن

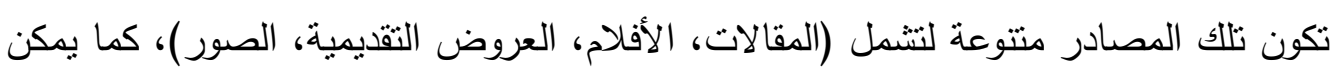
الاستعانة بمصادر مطبوعة كالكتب والصحف والمجلات، فيجب تحري الدقة لمواقع وصفحات الويب لاختيار صفحات الويب المناسبة، ثم ربطها بالمهمة مما يساعد المتعلم على الاستفادة

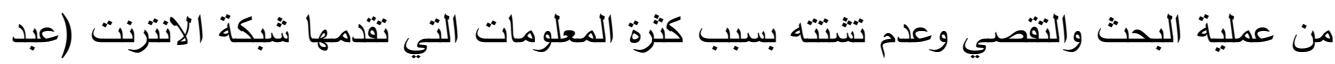
العزيز طلبة، 9 . . r، صو 9 (1). 


\section{ه- التقويم Evaluation:}

يعد التقويم معيارًا لقياس المهارات التي يتقنها المتعلم من خلال الأنشطة التي يقوم بها، التهاء

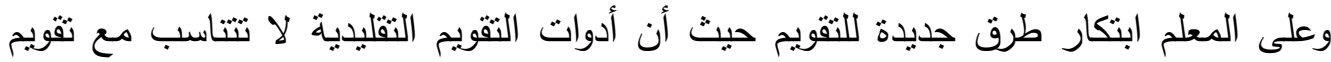

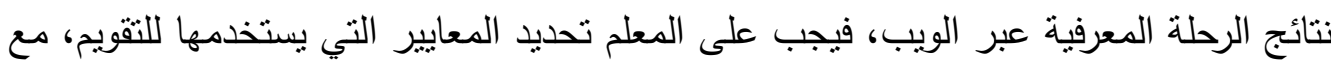

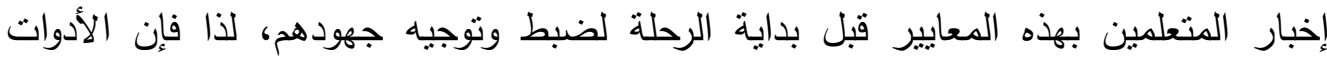

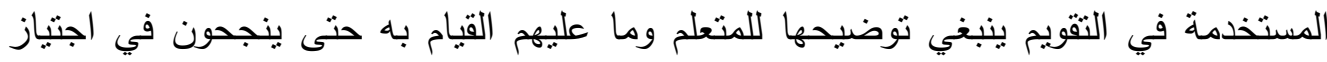
ماهو مطلوب منهم بكفاءة (Strickland, 2005, p.123).

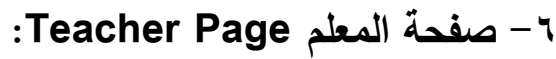

هي صفحة موجهة للمعلم ترفق بالرحلة المعرفية وتمثل دليلًا استرشاديًا للتوظيف الجيد

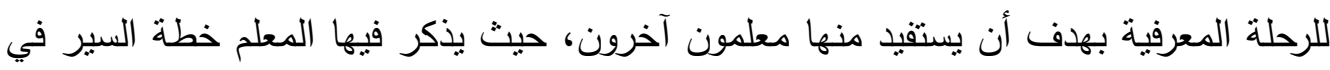

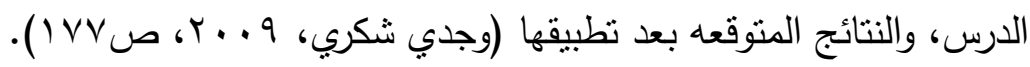

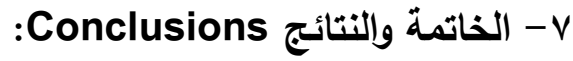

هي آخر مرحلة في الرحلة المعرفية، يتم فيها الانتهاء من الأنشطة، ثم يقوم المعلم

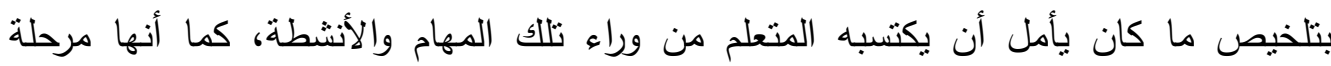

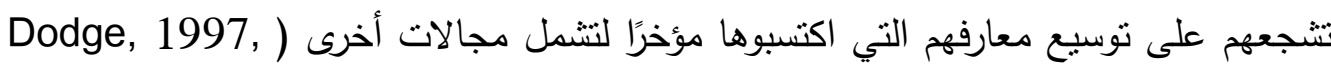
.(p.77

خصائص ومزايا الرحلات المعرفية عبر الويب: تتسم الرحلات المعرفية عبر الويب بالعديد من المزايا والخصائص، يمكن تلخيصها

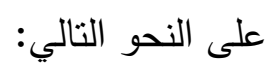
1- توفر وسيلة سريعة لتصفح مواقع شبكة الإنترنت دون البحث الذي بستغرق وقتًا طويلًا من

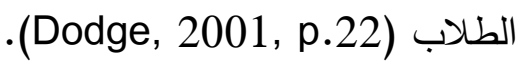
r- تنتح الفرصة لمن يقوم بإنشاء الرحلة بأن يكون بمثابة المراقب لمواقع الويب التي يتم زيارتها، وتوفير وسيلة آمنة لتجنب المواد غير اللائقة (Roblyer, 2006, p.145).

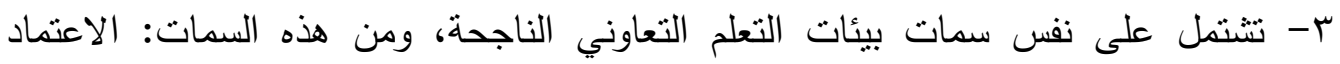

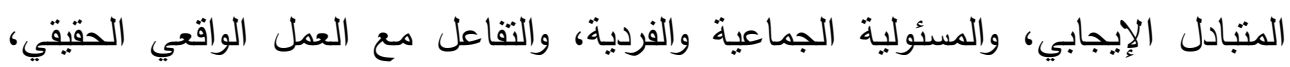

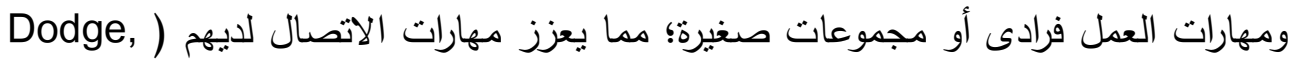
.(2001, p.23

ع- تهدف إلى تطوير قدرات الطالب الذهنية، وبناء باحث يستقصي المعلومة بنفسه، ويستطيع

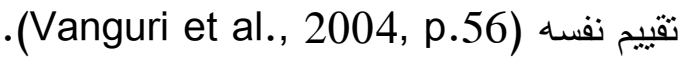
ه- وجود العناصر التحفيزية كإعطاء أدوار محددة للمتعلمين، أو تقديم موقف أو سيناريو للمتعلمين؛ الأمر الذي يزيد من دافعيتهم للتعلم (Siko, 2008, p.19). 


\section{المحور الثاني: نمط المساعدة (المعلم): تعريف نمط المساعدة (المعلم):}

تعرف بأنها شكل من أنشكال الدعم والمساعدة الذي يقدمه العنصر البشري الأكثر خبرة ومعرفة للمتعلم في صورة توجيهات وإرشادات وتلميحات تساعده على إنجاز المهمة وتحقيق

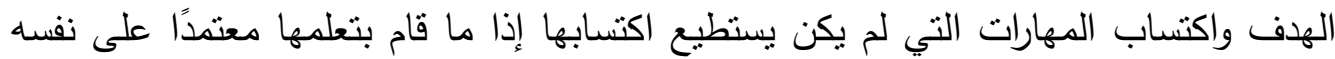
فقط، وقد يكون العنصر البشري هو المعلم، أو الخبراء أو الأقران الأكثر معرفة وخبرة .(Mathes, et al., 2003, pol, volman \& Beishuizen, 2012, P.68)

خصائص نمط المساعدة (المعلم): أنشار كل من كليم وكونيل (Klem and Connel,2004,P.48)، وهاريس وموجس

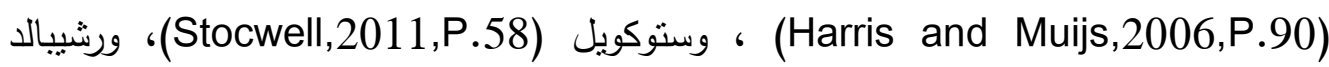
(Archibald, 2006, P.59) - النمذجة: حيث تقدم المساعدة نموذج السلوك التعليمي المراد تعلمه، من خلال توفير برنامج تعليمي لتوصيل ما يراد تعلمه.

- الانسحاب التدريجي: حيث تنخفض المساعدة المقدمة للمتعلم تدريجيًا، فكلما تقدم المتعلم في آداء المهمات التعليمية بشكل مستقل معتمدًا على ذاته، كلما انخفضت كمية المساعدة، فهو في حالة عدم احتياج لنفس كمية المساعدة؛ لذلك تندأ في التلاشي لتئي التدريجي حتى لا تعيق عملية الفهم والتقدم في آداء المهمات التعليمية. - التكيف: حيث تستخدم لمساعدة المتعلم على القيام بهمام معقدة لا يستطيع إنجازها بطريقة صحيحة، فهي تساعد في تتمبة مهارات القدرة على حل المشكلات، ولابد أن تتفق مع أسلوب تعلم المتعلمين.

- المساعدة: حيث تقدم المساعدة المطلوب للمتعلم، حتى يتمكن من آداء المهمة التعليمية بلاعتماد على نفسه.

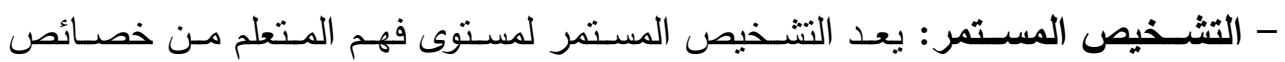
المساعدة التعليمية فهي تتطلب المعرفة المستمرة بقدرات المتعلم أثناء التقدم في عملية التعلم، ومن ثم تقدم له الأساليب والإستراتيجيات اللازمة لاعمه ومساعدته. 


\section{المحور الثالث: أسلوب التعلم (المعتمد/ المستقل):}

يمكن تعريف أسلوب التعلم (المعتمد/ المستقل) بأنه الطريقة التي ينزع بها الأفراد لتعلم

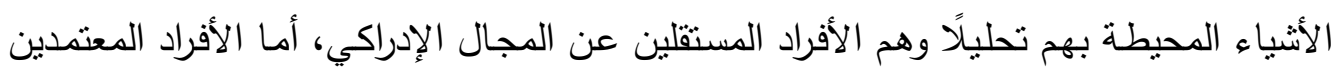
على المجال الإدراكي بنزعون إلى تعلم الأثنياء المحيطة بهم بطريقة شاملة وكلية مـع إهـال

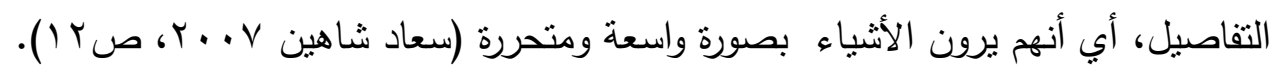
أهمية أسلوب التعلم (المعتمد/ المستقل): يعد أسلوب التعلم (المعتمد/ المستقل) أساسًا للتمييز بين الأفراد؛ حيث بيساعد في التتبؤ بسلوك المتعلمين في جميع المواقف، سواء المدرسية أو الاجتماعية أو الأسرية أو لوبن الثخصية، ويساعد المعلم في اختيار الأسلوب الأمتل لتوجيه الطلاب وإرشادهم، واختيار

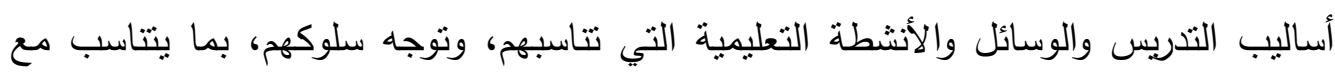

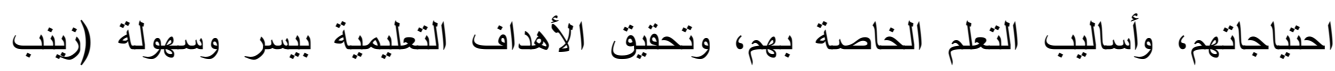

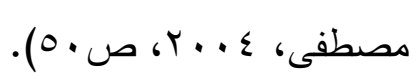

ويسهم هذا الأسلوب في توضيح أسلوب الفرد في تلقي المعلومات والمعارف، وأسلوبه

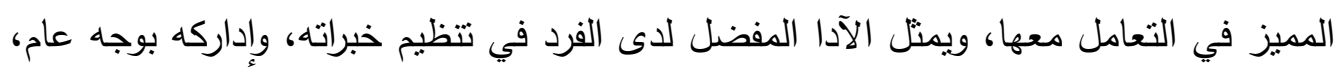

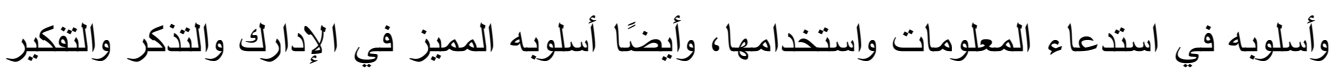

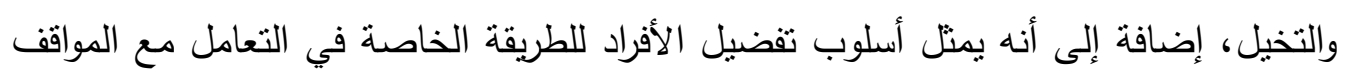

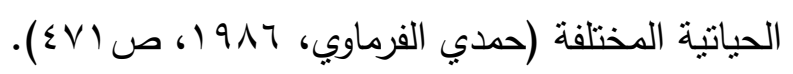

يتضح للباحثة مما سبق أن المتعلمون يتمايزون فيما بينهم وفقًا لأسلوب التعلم (المعتمد/

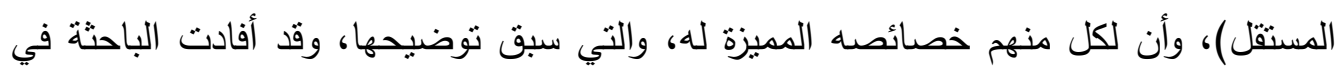

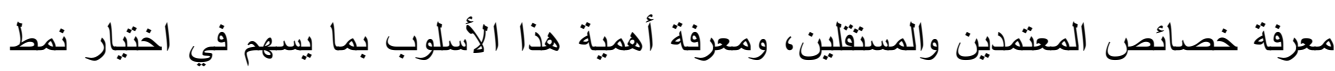
المساعدة الالكترونية الأمتل لكل أسلوب تعلم.

$$
\text { قياس أسلوب التعلم (المعتمد/ المستقل): }
$$

قامت الباحثة بالإطلاع على مقاييس أسلوب التعلم (المعتمد/ المستقل) مثل اختبار المؤشر والاطار Rod and Frame Test (R.F.T) لويتكن (1948) Witken، واختبار ضبط وضع الجسم Body Adjustment Test (B.A.T) لويتكن (1949) Witken واختبار الأشكال المتضمنة Embedded Figures Test (E.F.T)، واختبار الغرفة الدوارة 
The Overlapping واختبار الأشكال المنداخلة The Rotating Room Test (R.R.T) The Hidden Figures Test واختبار الأشكال المختفية Figures Test (O.F.T) (H.F.T)

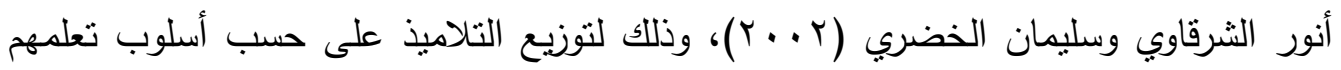
(المعتمد/ المستقل) في المحتوى التعليمي الخاص بمنهج العلوم للصف الثاني الإعدادي.

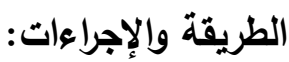
أ- منهج البحث: استخدمت الباحثة في بحثهاء الحالي: • المنهج الوصفي التحليلي: في عرض وتحليل الدراسات السابقة ونتائج هذه الدراسات لعمل قائمة بالمعايير الخاصة بتصميم نمط المساعدة (المعلم) المصاحب للرحلات المعرفية عبر الويب.

المـنهج شبه التجريبي: للتعرف على أثر استخدام نمط المساعدة (المعلم) واسلوب

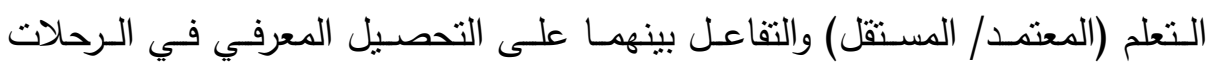

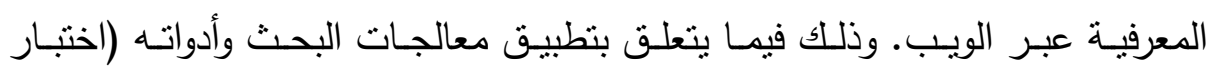

$$
\text { تحصيلي). }
$$$$
\text { ب- التصميم التجريبى للبحث: }
$$

قامت الباحثة باستخدام التصميم التجريبي r× آ مع التطبيق القبلي والبعدي للاختبار التحصبلى. جدول (1) التصميم التجريبي للبحث

\begin{tabular}{|c|c|c|c|}
\hline التطبيق البعدي & المعالجة التجريبية & التطبيق القبالي & \\
\hline \multirow{2}{*}{ التحصيلي } & \multirow{2}{*}{ الرحلة المعرفية عبر الويبب } & \multirow{2}{*}{ التحصيلي } & تلاميذ معتمدون \\
\hline & & & تلاميذ \\
\hline
\end{tabular}




\section{ج- مادة المعالجة التجريبية:}

تصميم موقع تعليمي قائم على الويب كرحلة معرفية لتتمية التحصيل المعرفي بمنهج

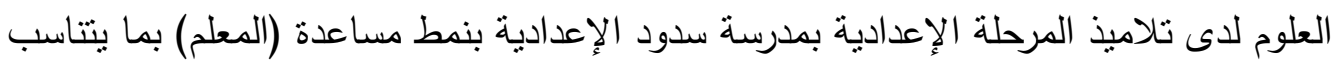
مع أسلوب التعلم الخاص بهم، نم تقسيمهم إلى مجموعتين تجريبينين، الأولى: تلاميذ معتمدون يستخدمون الرحلة المعرفية عبر الويب بنمط مساعدة (المعلم)، والثانية: تلاميذ مستقلون يستخدمون الرحلة المعرفية عبر الويب بنمط مساعدة (المعلم)،.

أدوات البحث: نم تصميم أدوات القياس بالبحث الحالي، وتمثلت هذه الأدوات فيما يلي: 1 - الاختبار التحصيلي المعرفي: يهدف هذا الاختبار إلى قياس الجوانب المعرفية لمنهج العلوم للصف الثاني الإعدادي

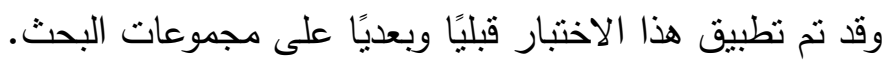

وفيما يلي شرح تفصيلي لخطوات وإجراءات إعداد هذا الاختبار :

تهدف الاختبارات التحصيلية بصفة عامة إلى قياس الجانب المعرفي لما تم تحقيقه أو تحصيله من أهداف خلال فترة زمنية معينة، وحيث إنه من أهداف البحث الحالي معرفة أثز

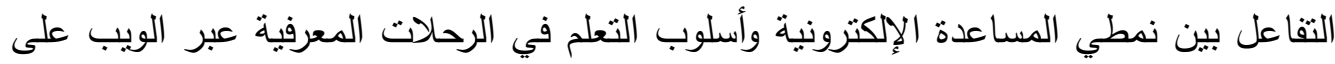

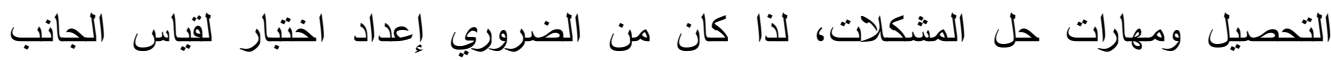
المعرفي، وتم إعداد الاختبار وفقًا للمراحل التالية:

(1) تحديد الهـف من الاختبار التحصيلي: اعدت الباحثة هذا الاختبار التحصيلي بهدف قياس الجانب المعرفي لتلاميذ الصف

$$
\begin{aligned}
& \text { الثاني الإعدادي في منهج العلوم. } \\
& \text { (r) تحديد نوع الأسئلة وعددها: }
\end{aligned}
$$

قامت الباحثة بإعداد جدول مواصفات الاختبار التحصيلي، بهدف التحقق من عدد الأسئلة لكل هدف، حيث نم الربط بين الأهداف المراد تحقيقها، وعدد الأسئلة التي تغطيها. 


\section{: (r) (r) صياغة مفردات الاختبار}

حددت الباحثة عدد الأسئلة، ونوعها، حيث تكون الاختبار التحصيلي من ( • (ه) مفردة،

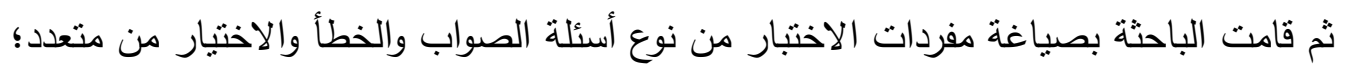
وقد تم اختيار هذه الانواع لسهولة تصحيح هذه الأنواع من الأسئلة إلكترونيًا وعمل مفتاح

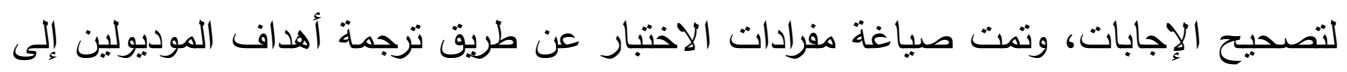
أسئلة.

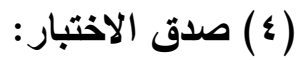

يقصد بصدق الاختبار مدى نجاحه في قياس الأهداف التعليمية التي صمم لقياسها،

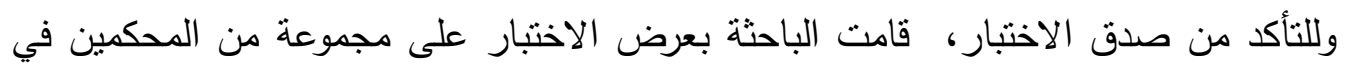
تخصص تكنولوجيا التعليم، لإبداء الرأي حول مدى وضوح تلعليمات الاختبار، ارتباط أسئلة

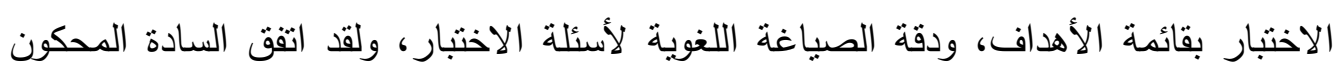

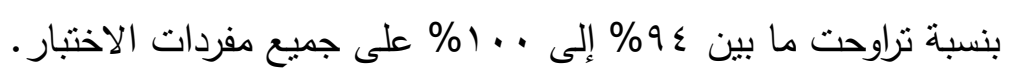

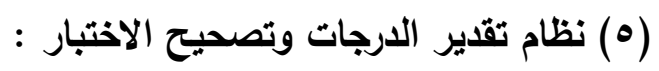
تم وضع درجة واحدة فقط لكل مفردة من مفردات الصواب والخطأ، ودرجة أيضًا لكل

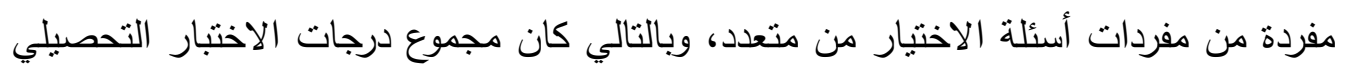
هو ( • ) درجة يحصل عليها كل تلميذ إذا كانت إجابته صحيحة على جميع مفردات الأسئلة. ( ) (") ضبط الاختبار:

تم ضبط الاختبار في ضوء مقترحات السادة المحكمين على الاختبار التحصيلي، وقد

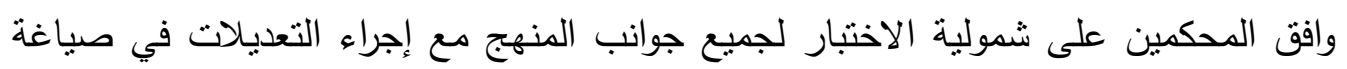
بعض الأسئلة.

(V) الصورة النهائية للاختبار التحصيلي: (V) تم إجراء التعديلات في ضوء التجربة الاستطلاعية التي قامت بهائها الباحثة، وبذلك أصبح الاختبار في صورته النهائية. 


\section{( ) التجرية الاستطلاعية للاختبار التحصيلي:}

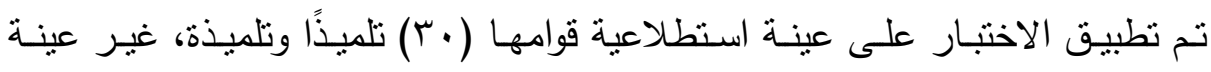

$$
\begin{aligned}
& \text { البحث الأساسية وتم رصد درجات التلاميذ؛ بغرض تحديد كلًا من: } \\
& \text { أ. الزمن اللازم للإجابة عن مفردات الاختبار . } \\
& \text { ب. حساب ثنات الاختبار . }
\end{aligned}
$$

أ- تحديد الزمن المناسب للاختبار: وذلك عن طريق جمع الزمن الذي استغرقه أول تلميذ

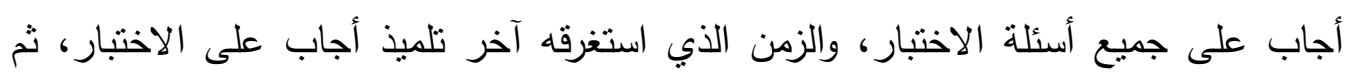

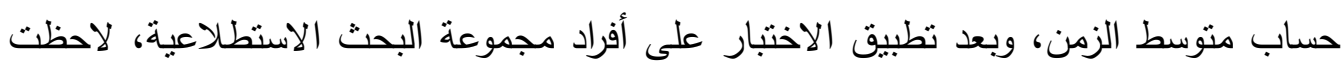

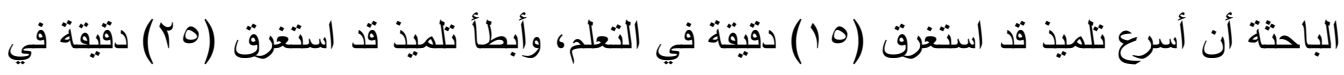

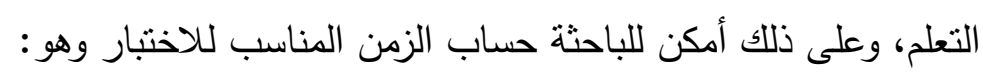

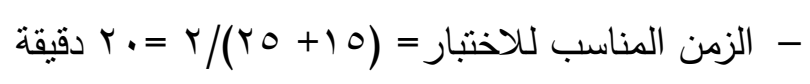

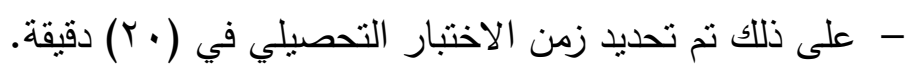

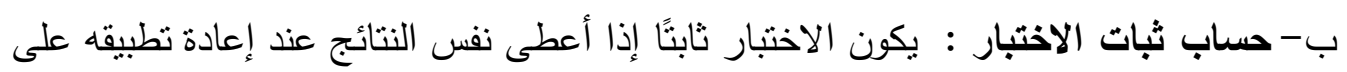
نفس الأفراد وفي نفس الظروف والهدف من قياس ثبات الاختبار هو معرفة مدى خلو الاختبار

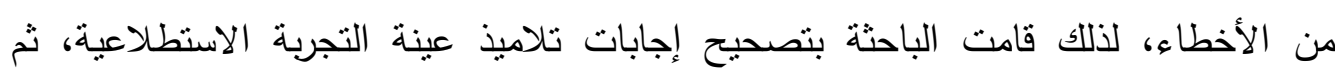
رصدت درجاتهم وقد قامت الباحثة بإدخال البيانات على حزمة البرامج ومعالجتها الإحصات ناتيائية SPSS

\begin{tabular}{|c|c|c|c|}
\hline القيمة & مفردات الاختبار & عدد العينة & معامل الثبات \\
\hline 0.85 & 0. & $r$. & معامل ألفا \\
\hline
\end{tabular}

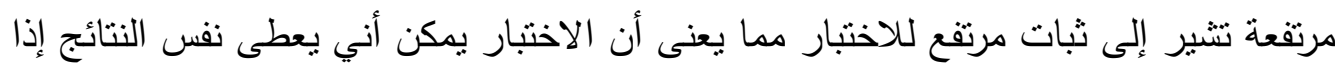

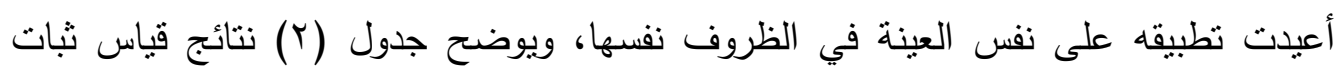

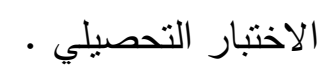


(9) برمجة الاختبار التحصيلي وإنتاج الاختبار إلكترونيًا: تم برمجة الاختبار التحصيلي ووضعه ضمن مكونات بيئة الرحلة المعرفية عبر الويب، بحيث يقدم للتلميذ في صورة إلكترونية كما يلي: بلئ - قبل البدء في دراسة الموديولين الخاص بمنهج العلوم للصف الثاني الإعدادي.

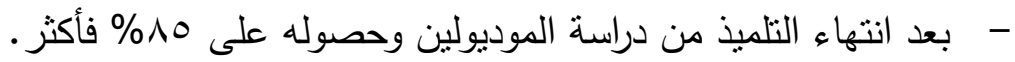
اختبار صحة الفروض البحثية وتفسيرها والتوصيات والبحوث المقترحة:

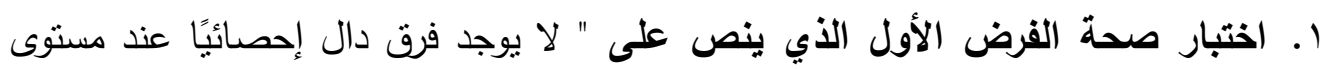

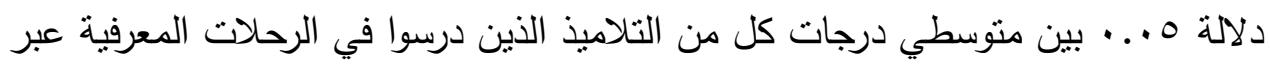
الويب يرجع إلى التأثير الأساسي لنمط المساعدة (المعلم) في التطبيق البعدي للاختبار التحصيلي". وللتحقق من صحة الفرض تم استخدام نتائج التطبيق البعدي للمجموعتين Two Way التجريبيتين في الاختبار التحصيلي، باستخدام تحليل التباين ثنائي الاتجاه

$$
\text { ANOVA }
$$

جدول(r) تحليل التباين ثنائي الاتجاه للاختبار التحصيلي البعدي

\begin{tabular}{|c|c|c|c|c|c|c|}
\hline مستلة الدلالة & الدلالة & قيمة (ف) & متوسط & درجات & مجموع المربعات & مصدر التباين \\
\hline دالة & .362 & .845 & 8.067 & 1 & A.. TV & نمط المساعدة \\
\hline دالة & .739 & .112 & 1.067 & 1 & $1 . .7 V$ & أسلوب التعلم \\
\hline \multirow[t]{3}{*}{ دالة } & .012 & 6.712 & 64.067 & 1 & $7 \varepsilon . .7 V$ & نمط المساعدة×أسلوب \\
\hline & & & 9.545 & 07 & سז. & الخطأ \\
\hline & & & & 7. & ITVK..... & المجموع \\
\hline
\end{tabular}

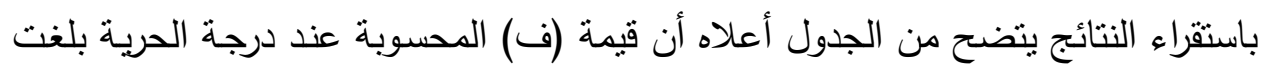

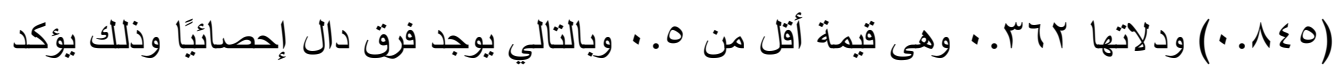
وجود تأثير لنمط المساعدة (المعلم) على القياس البعدي للاختبار التحصيلي المعرفي وبالتالي وني 
تم رفض الفرض الصفري وقبول الفرض البديل الذى ينص على "يوجد فرق دال إحصائيًا عند مستوى دلالة ه ... بين متوسطي درجات كل من التلاميذ الذين درسوا في الرحلات المعرفية عبر الويب يرجع إلى التأثير الأساسي لنمط المسـاعدة (المعلم) في التطبيق البعدي للاختبار التحصيلي"

r. اختبار صحة الفرض الثاني الذي ينص على "لا يوجد فرق دال إحصائيًا عند مستوى

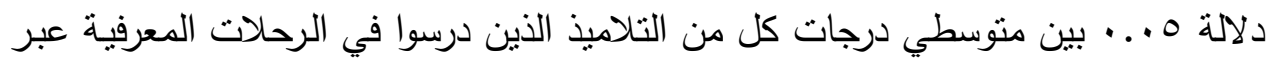

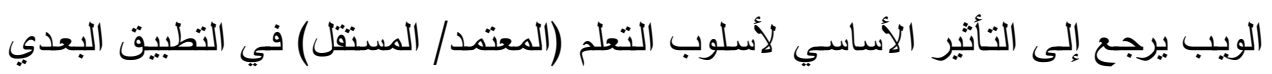
للاختبار التحصيلي".

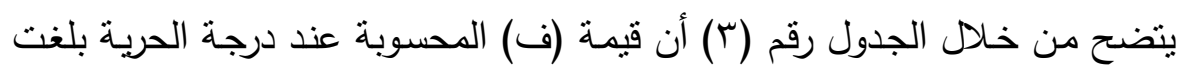

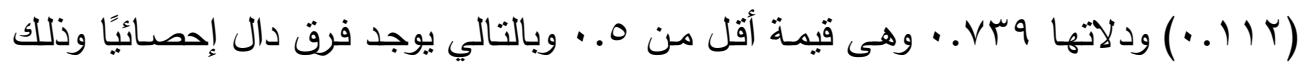
يؤكد وجود تأثير لأسلوب التعلم (المعتمد/ المستقل) على القياس البعدي للاختبار التحصيلي وبالتالي تم رفض الفرض الصفري وقبول الفرض البديل الذى ينص على لائى أنه "يوجد فرق دال

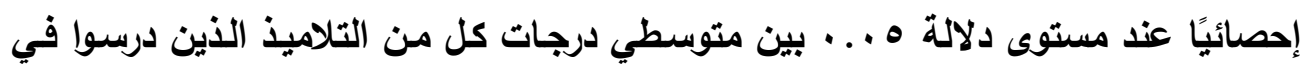
الرحلات المعرفية عبر الويب يرجع إلى التأثير الأساسي لأسلوب التعلم (المعتمد/ المستقل) في التطبيق البعدي للاختبار التحصيلي".

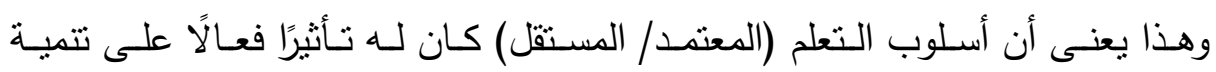

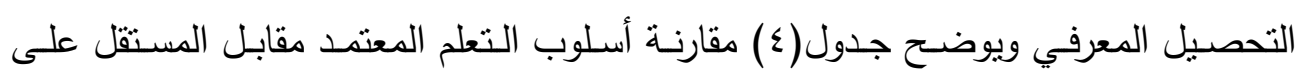
الاختبار التحصيلي لتحديد أيهما أكثر تأثنرًا وذلك باستخدام اختبار المقارنات الثنائية.

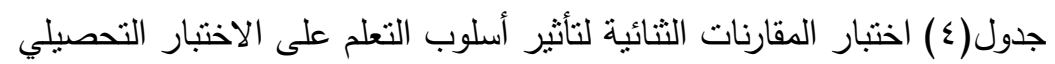

\begin{tabular}{|c|c|c|c|c|c|c|c|c|}
\hline الدلالة & متوسط & الإنحراف & المتوسط & أعلى & درجة & عدد & \multicolumn{2}{|c|}{ مقارنة بين أسلوب } \\
\hline 0 & $\begin{array}{c}- \\
\text { r.v... }\end{array}$ & 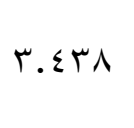 & $\leqslant 0 . \Lambda$. & 0 . & "ᄉ & r. & مستقل & معتمد \\
\hline 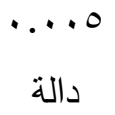 & r.V.. & r...17 & $\leq 7 . \cdot V$ & 0. & rq & $r$. & معتمد & مسنقل \\
\hline
\end{tabular}


باستقراء النتائج يتضـح من الجدول أعلاه أن أسلوب التعلم المستقل أكثر تأثيرًا وذك لأن

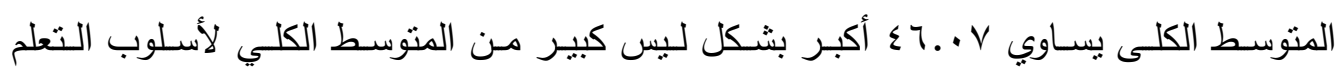

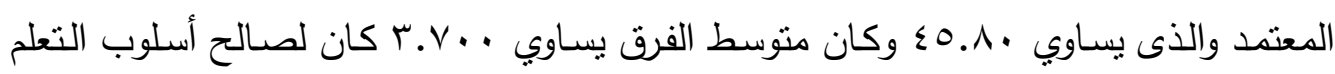

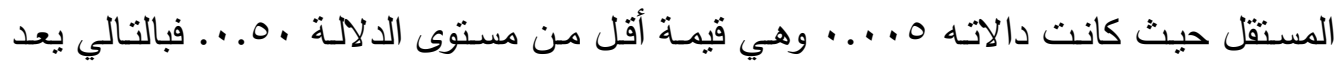
الفرق دال إحصائًا وهذا يؤكد على وجود الفرق لصالح أسلوب التعلم المستقل.

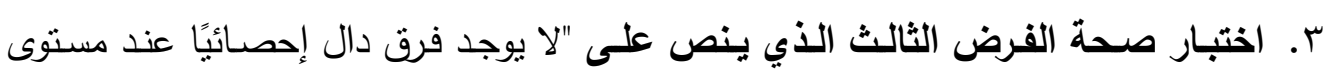
دلالة ه . . . بين متوسطات درجات كل من التلاميذ الذين درسوا في الرحلات المعرفية

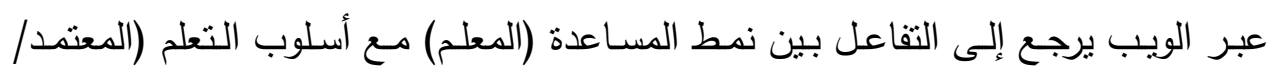
المستقل) في التطبيق البعدي للاختبار التحصيلي".

يتضح من خلال الجدول رقم (r) أن قيمة (ف) المحسوبة عند درجة الحريـة بلغت

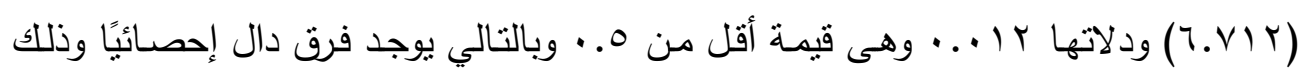

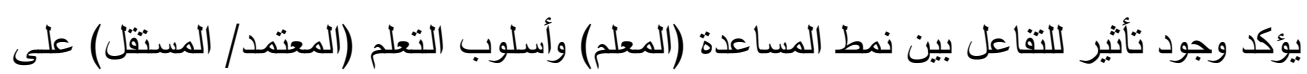

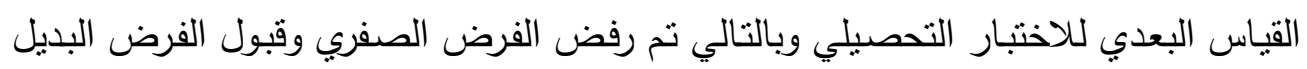

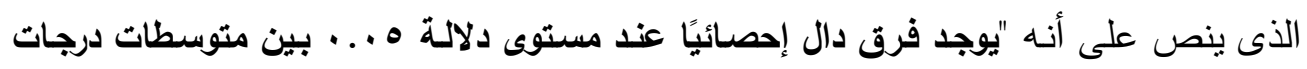

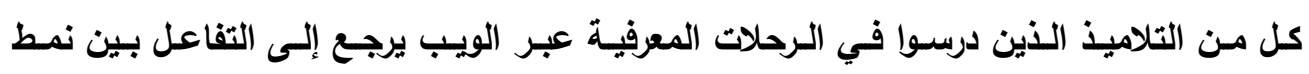
المساعدة (المعلم) مع أسلوب التعلم (المعتمد/ المستقل) في التطبيق البعدي للاختبار التحصيلي". وهـا يعنى أن التفاعـل بـين نمـط المسـاعدة (المعلم) وأسـلوب التعلم (المعتمـد/

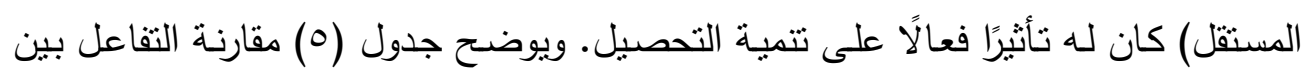

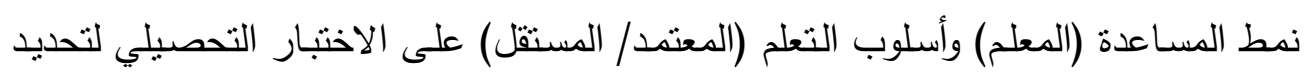
أيهما أكثر تأثنيرًا وذلك باستخدام اختبار المقارنات الثنائية. جدول (0) اختبار المقارنات الثنائبة لتأثثر التفاعل بين نمطي المساعدة وأسلوب التعلم على الاختبار التحصبلي

\begin{tabular}{|c|c|c|c|c|c|c|}
\hline الإنحراف & المنوسط & أعلى & درجة & العينة & \multicolumn{2}{|c|}{ مقارنة التفاعل بين نمط } \\
\hline & & & & & نمط & أسلوب \\
\hline 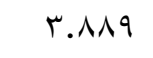 & $\leqslant 7 . \leqslant V$ & 0. & Tᄉ & 10 & معلم & معتمد \\
\hline r.ONT & $\varepsilon \varepsilon .7 V$ & 0. & rq & 10 & معلم & مستقل \\
\hline
\end{tabular}


باستقراء النتائج يتضـح من الجدول أعلاه أن المجموعة التجريبية الأولى التي درست في الرحلات المعرفية عبر الويب القائمة بنمط مساعدة (المعلم) بأسلوب التعلم (المعتمد) أكثر تأثيرًا

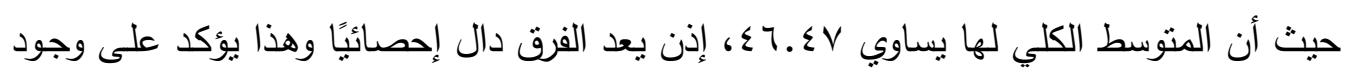
الفرق لصالح المجموعة التجريبية الأولى. توصيات البحث: - ت

في ضوء ما أسفرت عنه نتائج البحث الحالي توصي الباحثة بالآتي: - الاستعانة بقائمة معايير تصميم المحتوى الإلكتروني القائم على الرحلات المعرفية عبر بالئ

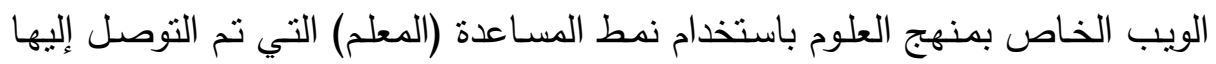

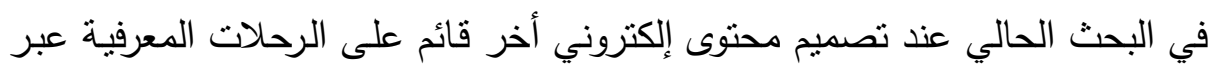
الويب لتتمية التحصيل المعرفي لدى تلاميذ المرحلة الإعدادية.

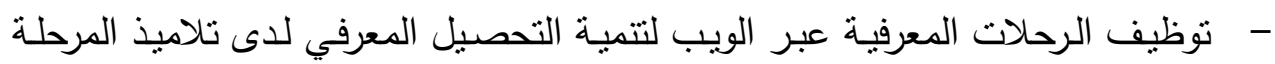
الإعدادية. - - دعم الاتجاه نحو استخدام الرحلات المعرفية عبر الويب بجانب استراتيجيات التدريس

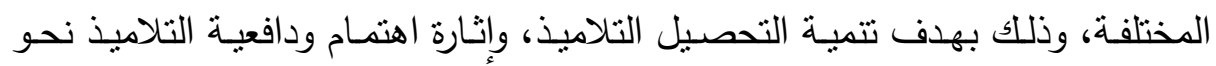
التعلم؛ لتحسين العملية التعليمية. - تشـيع المعلمـين على اسـتخدام الـرحلات المعرفيـة عبر الويب، في تـدريس المـواد الدراسية المختلفة. - أهميـة تصميم بعض الموضـوعات والمنـاهج الدراسية في شكل رحسلات معرفيـة يقوم بتتفيذها التلاميذ عبر الويب. - - تأهيل تلاميذ المرحلة الإعدادية على استخدام الرحلات المعرفية عبر الويب في تتفيذ وإدارة الأنشطة التعليمية.

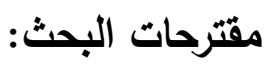

في ضوء ما توصل إليه البحث من نتائج يمكن طرح الموضوعات البحثية التالية:

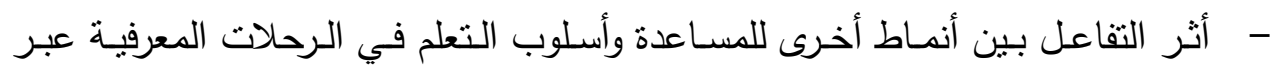
الويب في تتمية التحصيل لدى تلاميذ المرحلة الإعدادية. - فاعلية تصميم الرحلات المعرفية عبر الويب في تتمية مهارات التعلم التشاركي.

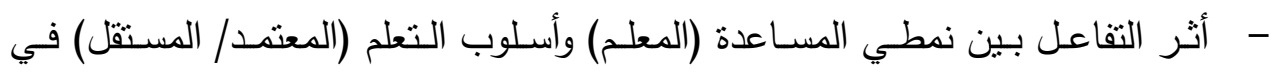
الرحلات المعرفية عبر الويب على مهارات التفكير الابتكاري. 


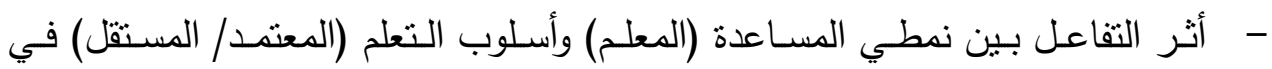
الرحلات المعرفية عبر الويب على مهارات التنظيم الذاتي. - إجراء دراسة شبيهة بالدراسة الحالية على تلاميذ وطلاب مراحل تعليمية مختلفة ومناهج مختلفة.

- - - - مراء دراسة مماتلة للدراسة الحالية على مراحل دراسية ومستويات تحصيلية مختلفة. - - دراسة أثر المتغير المستقل للبحث الحالي على مهارات التظظيم الذاتي والتعلم الذاتي. 


\section{قائمة المراجع:}

\section{أولًا: المراجع العربية:}

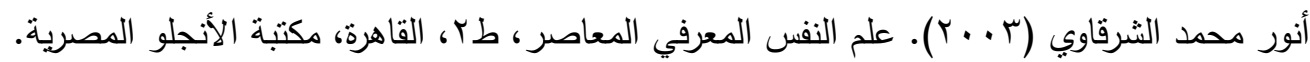

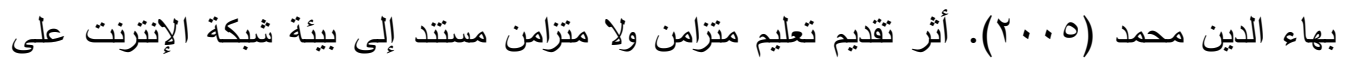
تتمية مهارات المعتمدين والمستقلين عن المجال الادراكي لوحدة تعليمية لمقرر منظومة الحاسب لدى طلاب شعبة إعداد معلم الحاسب الآلي بكليات التربية النوعية (رسالة ماجستير). معهد الدراسات التربوية- جامعة القاهرة، القاهرة. حمدي الفرماوي (ד^و (1). الأساليب المعرفية ومفهوم التمايز السيمانتي، الكتاب السنوي في علم النفس، المجلد الخامس، القاهرة: الأنجلو المصرية.

زينب عاطف مصطفى (ع . . Y). أثز التفاعل بين الأسلوب المعرفي واستخدام الكمبيوتر على تحصيل طالبات كلية الاقتصاد المنزلي في مادة حفظ الأغذية واتجاهاتهم نحو الكمبيوتز ، مجلة كلية

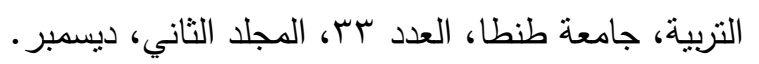

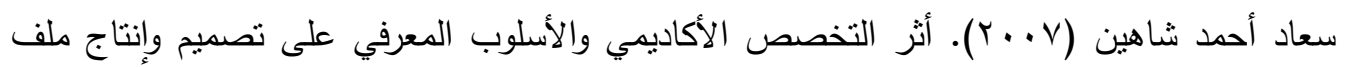
الإنجاز الإكتروني E-Portfolio لدى الطلاب المعلمين بكلية التربية. مجلة تكنولوجيا

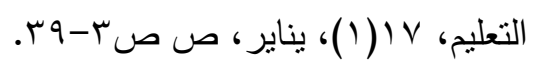

طارق عبد السلام ( • ( ب). أثز التفاعل بين مستويات المساعدة (الموجزة، والمتوسطة، والتفصيلية)، وبين أساليب التعلم، على تتمية كفايات تصميم التفاعلية ببرامج الوسائط المتعددة لطلاب

أخصائي تكنولوجيا التعليم (رسالة دكتوراه). كلية البنات، جامعة عين شمس.

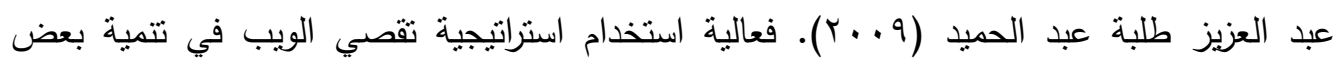
مستويات التفكير والقدرة على اتخاذ القرار نحو مواجهة تحديات التحديث التعليمي التكنولوجي، مجلة تكنولوجيا التعليم، سلسلة بحوث ودراسات محكمة، الجمعية المصرية

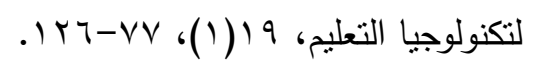

محمد أبو حطب (Y I • (Y). الويب كويست، (WwW.mohatab.arabblogs.com/files/123703.doc).

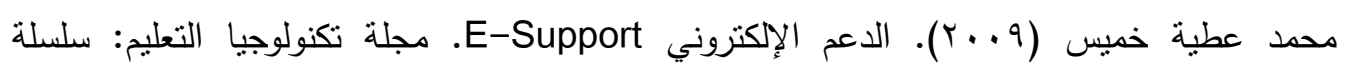

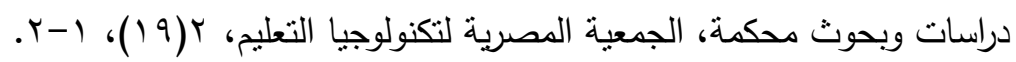

محمد عطية خميس (9 . . r). تكنولوجيا التعليم والتعلم. القاهرة، مكتبة دار السحاب. منال عبد العال مبارز، حنان محمد ربيع (9 . . ب). أثز استراتيجية تقصي الويب في تتمية مهارات البحث والاستقصاء في مقرر الحاسب الآلي لدى طلاب المرحلة الثانوية. مجلة نكنولوجيا

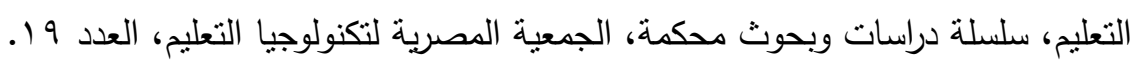

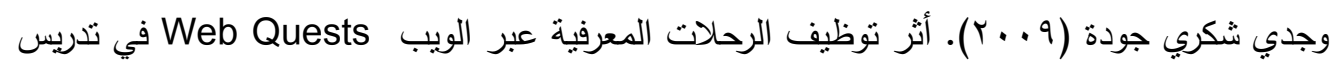
العلوم على تتمية التتور العلمي لطلاب الصف التاسع الأساسي بمحافظات غزة، الجامعة الإسلامية .غزة، كلية التربية. 


$$
\begin{aligned}
& \text { وداد عبد السميع إسماعيل، ياسر بيومي أحمد (1 . . r). أثز استخدام طريقة الويب كويست في تدريس } \\
& \text { العلوم على تتمية أساليب التفكير والاتجاه نحو استخدامها لدى طالبات كلية التربية. دجلة } \\
& \text { دراسات عربية في التربية وعلم النفس، يناير، العدد ( ()، المجلد (Y). } \\
& \text { ثانيًا: المراجع الأجنبية: }
\end{aligned}
$$

Alias, N. A. (2005). The Supportive Distance Learning Environment: A Study On The Learning Support Needs Of Malaysian Online Learners. The European Journal Of Open, Distance And E- Learning (EURODL). Retrieved June 19, 2011 From Http:// Www.European Journal Of Open, Distance And ELearning.3.Htm.

Archibald, D. (2009). Peer Review Locks Gate. Retrieved Jan 2, 2012 From Http://Quadrant.Org.Au/Opinion/Doomed-Planet/2009/11/Peer-ReviewLocks-Gate/

Dodge, B. (1997). Some Thoughs About Webquests, The Webquest Page. Retrieved From:

Dodge, B. (2002). The Webquest Design Process, San Diego State University, Educational Technology Department Web Site. Retrieved From: Http://Www.Webquest.Sdsu.Edu/Designsteps/Index.Html.

Harris, A., \& Muijsa, D. (2006). Teacher Led School Improvement: Teacher Leadership In The UK. Teaching And Teacher Education, 22 (8), 921-972.

Ikpeze, H. \& Boyd, F (2007). Web-Based Inquiry Learning: Facilitating Thoughtful Literacy With Web Quests. The Reading Teacher Journal, 60(7), 644- 654.

Klem, A., \& Connel, J (2004, September). Linking Teacher Support To Student Engagement And Achievement. Journal Of School Health, 74(7), 124- 156.

Lee, Y. J. (2012). Developing An Efficient Computational Method That Estimates The Ability Of Student In A Web- Based Learning Environment. Computers And Education, 58, Pp. 579-589.

Peterson, C. Caverly, D. (2003). Techtalk: Developing Academic Literacy Through Webquests, Journal Of Developmental Education, 26(3), 38-41.

Robert, Z. Et Al. (2006). Webquest Learning As Perceived By Higher Education Learners, Techtrends, 49(4), 41-49.

Stocwell, G. (2011). Online Approaches To Learning Vocabulary: Teacher- Centered Or Learner- Centered?. International Journal Of Computer- Assisted Language Learning And Teaching, 1(1), Pp. 134-144.

Stoks, G. (2002). Webquest: Task-Based Learning In A Digital Environment, Babylonia, 3, 56-58.

Stricland, J. (2005). Using Webquests To Teach Content: Comparing Instructional Startegies, Contemporary Issues In Technology And Teacher Education, 5(2), 138-148.

Vanguri, P., Sunal, C., Wilson, E., \& Wright, V. (2004). Webquest In Social Studies Education, Journal Of Interactive On Line Learning. The University Of Alabama, Vol. 3, No. 2. 